\title{
Safety First? The Role of Emotion in Safety Product Betrayal Aversion
}

\author{
ANDREW D. GERSHOFF \\ JONATHAN J. KOEHLER
}

\begin{abstract}
Consumers often face decisions about whether to purchase products that are intended to protect them from possible harm. However, safety products rarely provide perfect protection and sometimes "betray" consumers by causing the very harm they are intended to prevent. Examples include vaccines that may cause disease and air bags that may explode with such force that they cause death. Expanding research on betrayal aversion, this study examines the role of emotions in consumers' tendency to choose safety options that provide less overall protection in order to eliminate a very small probability of harm due to safety product betrayal. In five studies we find that betrayal aversion is reduced and safer alternatives are selected when factors that dampen the emotional response to potential betrayals are introduced or taken into account. These factors include changing the betrayal from an action to an omission (study 1), introducing positive imagery (study 2), introducing visual representations of risk (study 3 ), making the decision for another rather than oneself (study 4), and intuitive thinking style (study 5).
\end{abstract}

\begin{abstract}
A growing number of researchers have stressed the importance of examining the decisions consumers make to protect their health and well-being (Chandran and Menon 2004; Hoffer and Peterson 1994; Menon, Block, and Ramanathan 2002; Thompson 2005). Many of these decisions include an emotional element that may influence-if not determine-the choices that people make (Drolet and Luce 2004; Loewenstein et al. 2001; Sunstein 2005).

Consider, for example, people who must decide whether or not to purchase safety products and services that are intended to protect them from possible harm. Car shoppers decide whether to pay extra for antilock brakes and air bags that may help them avoid or survive a crash. Patients decide whether to seek vaccinations for themselves and their chil-

Andrew D. Gershoff (andrew.gershoff@mccombs.utexas.edu) is an associate professor of marketing at the Red McCombs School of Business, University of Texas at Austin, 1 University Station, B7202, Austin, TX 78712. Jonathan J. Koehler (jay.koehler@ northwestern.edu) is the Beatrice Kuhn Professor of Law at Northwestern University School of Law, Chicago, IL 60611. The authors thank Vildan Altuglu, Cecile Cho, Anat Keinan, Anirban Mukhopadhyay, and Martin Zemborain for their help with data collection.
\end{abstract}

John Deighton served as editor and Steve Hoch served as associate editor for this article.

Electronically published January 27, 2011 dren that may protect them from disease. Outdoor enthusiasts consider sunscreens, flotation devices, and spray repellants that may provide protection from skin cancer, drowning, and unwanted outdoor intruders.

The standard economic analysis holds that people should purchase these products if the total expected benefits of owning and using them outweigh their total expected costs. Such computations are difficult because most safety products do not deliver perfect protection and the risks of failure are often unknown or task dependent. No one can say exactly how much drivers who purchase antilock brakes decrease their risk of dying in an accident because the extra protection these brakes provide depends on road conditions, speed, tires, braking style, and so on.

A standard analysis is further complicated by the paradoxical problem that some safety products may "betray" consumers by causing the very harm they are supposed to prevent. Air bags occasionally kill people who experience survivable car crashes (Meyer and Finney 2005), vaccines occasionally cause disease (Ellenberg and Chen 1997), and even bear repellant occasionally attracts bears (Matthews 1999).

Koehler and Gershoff (2003) first examined how people respond to safety product betrayals in a variety of contexts. In one study, participants were asked to assume that they were indifferent between two rental apartments, each of 
which was equipped with one of two smoke alarms. Next, they learned that there were differences between the two alarms. Some participants were told that in the event of a nighttime fire due to the usual causes, occupants in the apartment equipped with Alarm One had a 2\% chance of dying while occupants in the apartment equipped with Alarm Two had only a $1 \%$ chance of dying. However, they were also told that the wiring of Alarm Two was such that it sometimes causes electrical fires that increase the risk of dying in a nighttime fire by an additional $0.01 \%$. In other words, Alarm One was associated with a $2 \%$ risk of death and Alarm Two was associated with a $1 \%+0.01 \%$ (betrayal) risk of death. Most participants in this condition preferred the apartment equipped with Alarm One even though they were nearly twice as likely to die with this safety device. Koehler and Gershoff (2003) explained this result as an aversion to the risk that the smoke alarm would betray its implicit promise to protect renters by causing the very harm that it was supposed to guard against. When the $0.01 \%$ betrayal risk associated with Alarm Two was replaced by a mathematically identical nonbetrayal risk, namely, an elevated risk of structural collapse, most people selected the alarm that was associated with the lower overall risk of death $(1.01 \%)$. This pattern of choices was observed for a large majority of participants across a variety of scenarios and dependent measures.

It is not surprising that consumers consider the risk of betrayal when choosing among safety devices. The mere possibility of betrayal threatens the social order that enables us to trust the safety infrastructure of our society, causing intense visceral reactions and negative emotions toward the betrayer (Koehler and Gershoff 2003). Unfortunately, these strong negative emotions toward a potential betrayer may also lead people to take unwise risks. For instance, one of the most commonly cited reasons $(21 \%)$ that people did not intend to be vaccinated against H1N1 influenza was an unfounded concern about contracting $\mathrm{H} 1 \mathrm{~N} 1$ from the vaccine itself (Blendon et al. 2009).

What are the factors that might reduce safety product betrayal aversion? The strong association between betrayal aversion and negative emotions reported in Koehler and Gershoff (2003) provides a starting point for this investigation. Participants who were confronted with safety product betrayal reported greater feelings of anger, resentment, anxiety, fear, sadness, and disgust compared to when there was no safety product betrayal, both after a harm had occurred (see study 4) and when faced with the risk of a potential for harm (see study 5). If fear and other negative emotions caused by a potential betrayal lead to avoiding a safety product, then betrayal aversion may be reduced or eliminated by introducing factors that dampen the negative emotion consumers feel. Below we review evidence that emotion plays a critical role in risky decision making in general and in safety decisions in particular.

\section{EMOTION AND BETRAYAL BY SAFETY DEVICES}

Research suggests that people rely on two distinct yet interactive "systems" for decision making (Chaiken and Trope 1999; Epstein et al. 1996; Kahneman and Frederick 2002; Pacini and Epstein 1999; Sloman 1996; van Gelder, de Vries, and van der Pligt 2009). System 1 is an automatic, nondeliberative system that quickly generates impressions of available stimuli. It is the experiential or emotional system. System 2 monitors the quality of System 1 impressions using a more deliberative judgment process. System 2 is the analytical or rational system.

Research on how people evaluate risky options points to the importance of System 1 (the emotional system). Studies show that people commonly make judgments and decisions under uncertainty based on nonprobabilistic rules (Rottenstreich and Kivetz 2006), visceral urges (Loewenstein 1996), affective evaluations of stimuli (Baumeister et al. 2007; Finucane et al. 2000; Mellers et al. 1997; Slovic et al. 2005), and gut feelings (Hsee and Weber 1997; Loewenstein et al. 2001; Slovic and Peters 2006; Weber and Milliman 1997). Consider, for example, Loewenstein et al.'s (2001) risk-asfeelings hypothesis. It argues that feelings such as worry, dread, and fear drive decisions in ways that cannot be reconciled with an analytical assessment of the underlying risks. Identical risks may be treated differently due to differences in feelings about available options or feelings present at the time of evaluation. Thus, watching an anxietyprovoking video prior to purchasing a new car can shift preferences toward a safer car over one that is sportier and more luxurious (Raghunathan and Pham 1999).

In light of the demonstrated importance of System 1 on risky choice, we seek to reduce safety device betrayal aversion by dampening the negative emotions caused by betrayal risks. In a series of behavioral studies, we pursue this goal by introducing various factors that are likely to promote a more cognitive task appraisal.

\section{EMOTIONAL INFLUENCES ON BETRAYAL AVERSION}

The first factor that we consider is inspired by research on the omission and normality biases. The omission bias (sometimes referred to as the "actor effect"; see Zeelenberg, van der Pligt, and de Vries 2000) is the tendency to react to harmful actions more strongly than equally harmful omissions (Baron 2008; Richard, van der Pligt, and de Vries 1996). The normality bias is the tendency to react to bad outcomes that arise from abnormal circumstances more strongly than equally bad outcomes that arise from more ordinary circumstances (Prentice and Koehler 2003). These phenomena are relevant to betrayal research because the conventional betrayal risk is both an active and an abnormal risk. That is, a safety device in the betrayal paradigm has the potential to behave abnormally and may play an active role in causing harm. However, safety devices may cause or allow harm in 
other ways. For example, a safety device could fail to function properly and thereby passively allow a harm to occur. Alternatively, a safety device could function as it should, but the device may yet be an agent of harm due to failures elsewhere in the system. Because these alternative failures do not involve both active and abnormal harms, there may be less negative emotion stemming from them and so less aversion to these types of potential failure despite identical risk of harm. We examine this possibility in study 1 .

A second factor is the imagery that accompanies the presentation and description of safety device choice. There is evidence that affect-rich presentations that stir emotions promote a feeling-based evaluation of objects while affect-poor presentations promote analytical evaluations. Hsee and Rottenstreich (2004) studied the effect of such presentations on people's willingness to donate money to help save endangered pandas. They found that when the number of pandas to be saved was represented with affect-rich pictures of the animals, people were insensitive to the actual number of pandas being saved. This result is consistent with a feelingbased approach to the problem. However, when the number of pandas was represented as affect-poor dots, people made more analytical evaluations that were sensitive to the number of pandas. Similarly, in a study on factors that affect how people view threats associated with crime and car accidents, Berger (2007) found that presenting information in affectpoor graphical or statistical form increased rational judgments and decreased assessments of the seriousness of the threats relative to affect-rich anecdotal accounts. We examine whether positive imagery and statistical graphs decrease betrayal aversion and associated negative emotions toward potential betrayal in studies 2 and 3 .

We also examine whether betrayal aversion can be reduced by changing the recipient of the safety device from oneself to a stranger. This hypothesis fits well with anecdotal evidence that doctors are less prone to rely on emotional considerations when they are less emotionally involved with their patients (Sepkowitz 2004), and with academic studies that show that people make different choices for others than they make for themselves (Kray 2000). In his remarkable paper on the role of visceral factors in decision making, Loewenstein (1996) suggests that people underestimate the emotional responses of others, particularly when making decisions for them. The implication of this observation for our purposes is that emotion-laden risks, such as betrayal risks, may receive less weight when the decision maker and person who must live with the consequences of the decision are different people. Research supports this position. Faro and Rottenstreich (2006) and Hsee and Weber (1997) find that the choices that people make for unknown others in risky situations are more risk neutral than those that they make for themselves. Faro and Rottenstreich (2006) argue that this result arises from an "empathy gap" in which people underestimate the impact of emotional considerations for strangers, but not for themselves. We test the significance of this self-other factor for betrayal aversion in study 4 .

Study 5 examines the role that individual differences in thinking style may play in betrayal aversion. Although there is broad consensus in the psychological community about the validity of the two-system model of reasoning described previously (Kahneman 2003, 698), there is variability in the extent to which people typically rely on each of the systems. For example, in counterfactual thought, representativeness, and framing problems, people who favor an experiential thinking style are more likely to respond in a heuristic rather than analytical manner (Epstein et al. 1996; Shiloh, Salton, and Sharabi 2002). Because potential betrayal involves an emotional reaction, we expect that people who favor a more analytical style of thought will show less aversion to potential safety product betrayal.

In short, four of the five studies reported here investigate the effects of a variety of potentially emotion-dampening factors on betrayal aversion. The fifth study examines individual differences. We take the reality of betrayal aversion as a starting point, noting that it has been demonstrated by Koehler and Gershoff (2003) in numerous scenarios, including air bags, vaccines, smoke and fire alarms, and security guards. Throughout the studies presented here, we use a focused approach and hold the betrayal scenario constant (using the air bag malfunction scenario from Koehler and Gershoff, studies 4 and 5), which places a greater premium on internal rather than external validity, in order to increase our confidence in the interpretation of moderating effects.

\section{STUDY 1: TYPE OF BETRAYAL}

Safety products may be associated with harm in different ways. First, they may become agents of harm directly, as when an air bag deploys with such force that it kills a car's occupants (CNN 1998). In those cases, the air bag fails to act as it should and is the agent that actively delivers the harm. Second, safety products may simply fail to provide the expected protection and therefore be responsible for the resultant harm in a more passive manner. Such failures pose a significant public health concern (Reuters 2010). Third, safety devices may act as they should and yet be agents of harm due to failure elsewhere in the system. For example, a defective steering column may move an air bag closer to a driver, and the air bag may then become a proximate agent of harm in an accident. Here the safety device is indirectly responsible for the harm.

The air bag is associated with potential for harm in each of the three cases above, although the cases differ in how they violate expectations. Consequently, we hypothesize that the cases also differ in amount of negative emotions and correspondent betrayal aversion. The possibility that an air bag may actively cause death is a clear violation of a consumer's expectations for the safety device. The possibility that an air bag may fail likewise violates a consumer's expectations but does not violate the consumer's expectation that the device will not cause harm in an otherwise safe situation. Based on prior research that finds people have stronger emotional responses to harms that arise from actions rather than inactions, we hypothesize less negative 
emotion and less betrayal aversion to a passive safety device betrayal versus an active betrayal. Furthermore, when a safety device is the proximate agent of harm but has acted precisely as it was designed to act (indirect betrayal), there is a reduced sense in which the device has violated expectations. We therefore hypothesize less aversion to the indirect betrayal than either the active or passive betrayals.

\section{Method}

One hundred and twenty individuals were each paid $\$ 3.00$ for participating in study 1. Participants were recruited from the general public from a paid participant pool at the University of Michigan. In all conditions participants were offered a choice between two otherwise identical automobiles equipped with different air bags (Koehler and Gershoff 2003). For one of the cars, participants were told that "scientific crash tests indicate that there is a $2 \%$ chance that drivers who are in a serious accident [in this car] will be killed due to the impact of the crash." This was the higher overall risk option (2\%), and it was not associated with any risk of safety product betrayal. For the other car, participants were told that "scientific crash tests indicate there is a $1 \%$ chance that drivers who are in serious accidents risk death due to the impact of the crash" and that drivers of this car faced an additional "one chance in 10,000 (.01\%) risk of death." This is the lower overall risk option $(1.01 \%)$.

Three conditions varied the source of the additional $(.01 \%)$ risk. In the active betrayal condition the source of the additional risk of death was described as due to a potential action of the safety device, specifically, that "trauma caused by the force of the airbag deployment" could kill drivers and passengers who would not have been killed had they selected the other car (Koehler and Gershoff 2003, study 5). In the passive betrayal condition, the source of the additional $0.01 \%$ risk was described as due to a potential inaction of the safety device: "the airbag could fail to deploy" allowing some drivers and passengers to be killed who would not have been killed had they selected the other car. In the indirect betrayal condition, the source of the additional $0.01 \%$ risk was described as follows: "the engine block may jam the steering column. This may force the dashboard forward which may increase the forces of the deploying airbag. This may kill drivers and passengers who would not have been killed if their cars had been equipped with the other airbag."

Participants provided their preference between the two cars in each condition on a 7-point Likert-type scale anchored with "Definitely prefer option A" at 1 and "Definitely prefer option B" at 7. Next, participants were provided with a subset of items from the PANAS Negative Affect Scale (Watson, Clark, and Tellegen 1988), which was also used in Koehler and Gershoff (2003). Participants used a 5-point scale anchored by "Not at all" to "Extremely" to indicate how strongly they expected to feel various negative emotions (angry, afraid, jittery, sad) if they owned option B (i.e., the car with the lower overall risk air bag).

\section{Results}

A one-way ANOVA revealed significant differences in relative automobile preference depending on how the air bag might fail $(F(2,118)=19.37, p<.001$; see fig. 1$)$. As predicted, preference for the safer air bag (i.e., the $1.01 \%$ overall risk option) increased as the betrayal associated with the safer option became less acute. Thus, when the betrayal was passive rather than active, people had a stronger preference for the safer option $(M$ 's $=4.16$ and 2.80, respectively; $t(118)=4.40, p<.01)$, and when the betrayal was indirect rather than passive, people had an even stronger preference for the safer option $\left(M^{\prime}\right.$ 's $=4.80$ and 4.16 , respectively; $t(118)=1.99, p<.05)$.

We combined the four negative emotion items into a single measure $(\alpha=.92)$. A one-way ANOVA revealed a main effect for type of failure $(F(2,118)=9.18, p<.001)$. Planned comparisons showed that negative emotion for an active betrayal $(M=2.18)$ is greater than for a passive betrayal $(M=1.77 ; t(118)=2.23, p<.05)$ and negative emotion for a passive betrayal is greater than for an indirect failure $(M=1.32 ; t(118)=2.17, p<.05)$.

\section{Discussion}

Prior research showed that betrayal and exploitation of trust is associated with strong negative emotions and a visceral desire to distance oneself from the offending agent (Buunk 1982; Davis and Petretic-Jackson 2000; Medvec, Valley, and Thaler 1999; Robinson and Morrison 2000). Koehler and Gershoff (2003) found that this visceral desire induces people to choose safety options that increase the risk of the very harm they seek protection from. Study 1 extends the betrayal aversion phenomenon by showing that

\section{FIGURE 1}

STUDY 1: TYPE OF POTENTIAL BETRAYAL ON PREFERENCE FOR OVERALL LOWER RISK (1.01\%) AIR BAG OPTION

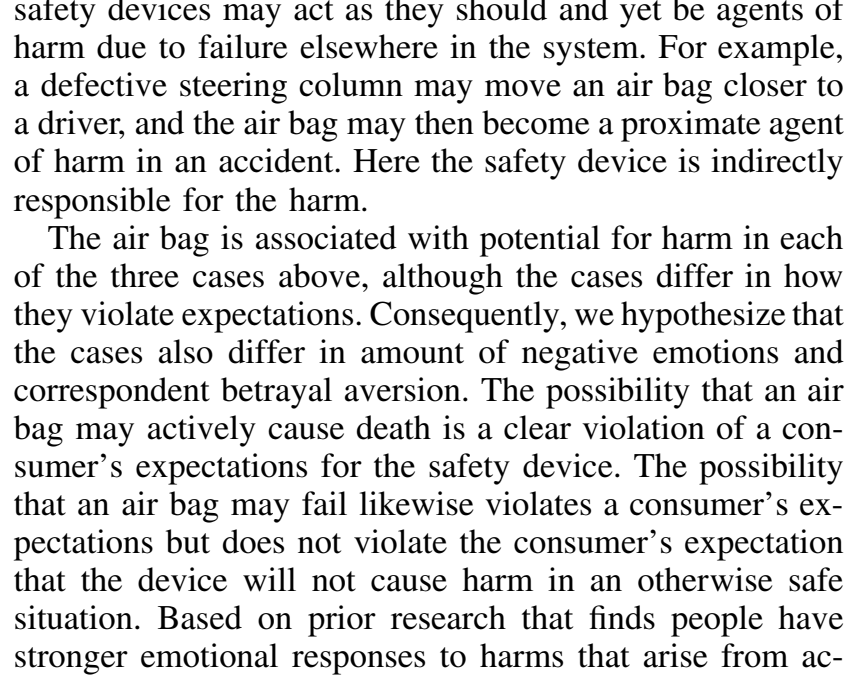


type of potential betrayal affects the emotional reactions people have to safety options and that those reactions are associated with degree of betrayal aversion. People apparently experience less negative emotion when betrayals are passive (i.e., the safety device fails to protect but does not actively cause harm) or indirect (i.e., the safety device functions properly but is nevertheless an instrument of harm due to failure elsewhere in the system), and betrayal aversion is correspondingly less acute.

These results suggest that betrayal and reactions to betrayal risk are not either-or phenomena. A safety product may betray consumers in various ways and to varying degrees, and the resultant emotion and aversion will be correspondingly graduated. In the remaining studies, we try to dampen the negative emotions that may influence betrayal aversion by introducing and/or measuring factors that are external to the nature of the betrayal.

\section{STUDY 2: IMAGERY}

The affective components of a risky choice situation may push consumers in the direction of evaluating available choice options on emotional System 1 grounds rather than analytical System 2 grounds (Chartrand, van Baaren, and Bargh 2006). In one probability assessment study, participants were less likely to collect necessary data and more likely to jump to conclusions following exposure to anxietyproducing stimuli (Lincoln et al. 2009). Similar findings have been reported in behavioral economics studies with the "ultimatum game" (Pillutla and Murnighan 1996; Sanfey et al. 2003). Andrade and Ariely (2009) found that $73 \%$ of people who were made angry prior to playing the ultimatum game (via a movie clip) rejected inequitable offers, but only $40 \%$ of people who were made happy rejected the identical offer.

The emotional response to betrayal risk may operate similarly. If so, then exposure to positive stimuli may reduce the negative emotions associated with betrayal risk and thereby weaken the betrayal aversion effect. We test this hypothesis in study 2 by exposing participants to images that are known to influence emotional states but that are unrelated to the safety device choice task. We predict that providing images that reduce people's negative feelings will interfere with emotion-based reasoning and increase preference for the lower overall risk safety option. Although our focus is on identifying factors that reduce betrayal aversion, the same logic suggests that images that increase negative feelings may exacerbate betrayal aversion.

\section{Method}

Two hundred and forty-six individuals were recruited through Amazon Mechanical Turk. Although demographics were not collected from this sample, a pretest sample of 158 participants was $53 \%$ female with a mean age of 35.5 , ranging from 18 to 63 years old. Each was paid the equivalent of $\$ 10$ per hour. The study was a 2 (betrayal: yes, no) $\times 3$ (imagery: negative, positive, none) betweensubjects design.

All participants read what was said to be an excerpt from a consumer magazine article. The article described new features in an automobile model, including two air bag options. The air bag options were described much as they were in study 1 (e.g., $2 \%$ risk vs. $1 \%+.01 \%$ risk). As in study 1 , the additional risk in the betrayal conditions was described as due to "trauma caused by the force of the airbag deployment." The additional risk in the no betrayal conditions was described as due to "causes other than the direct impact of the crash." We expected that participants would behave rationally and show greater preference for the lower $(1.01 \%)$ risk air bag when there was no possibility that it would be the cause of harm, regardless of images presented with the choice.

An ad for a photo contest that would appear in the next issue of the magazine appeared at the bottom of the page. In the positive and negative image conditions, this advertisement included six images. Images were selected from the International Affective Picture System, a set of images prescreened to produce specific premeasured emotional reactions (Lang, Bradley, and Cuthbert 2005). The positive images included a child eating watermelon, a deer drinking from a lake, a cow in a field, a family in a living room, a church on a hill, and a butterfly on a flower. The negative images included a dog baring its teeth, an armed robbery, a sinking ship, a tornado, and an attacking snake. In the no image control condition, no photos were displayed.

Participants read the excerpt and answered a question about it to ensure task attention. Next, those in the positive and negative image conditions used 5-point scales to rate the images on four positive (joyful, safe, relieved, relaxed) and four negative (afraid, angry, sad, jittery) emotions. Then, on a separate page, participants used a 7-point scale to indicate their air bag preference. Finally, participants estimated the amount of negative emotion (afraid, angry, sad, jittery) they would feel if they owned the car that had the lower overall risk (1.01\%) air bag.

\section{Results}

Manipulation Check. We combined participants' ratings of the four positive emotions $(\alpha=.95)$ and four negative emotions $(\alpha=.93)$ toward the images to create one positive and one negative emotional measure. An ANOVA revealed a main effect for imagery on the positive emotion measure, with images in the positive conditions rated more positively $(M=3.34)$ than images in the negative conditions $(M=1.13 ; F(1,149)=332.46, p<.001)$. Imagery ratings did not differ by betrayal condition, and there was no betrayal $\times$ imagery interaction (all $p$ 's $>.10$ ). Likewise an ANOVA revealed a main effect for imagery on the negative emotion measure with images in the negative conditions rated more negatively $(M=2.87)$ than images in the positive conditions $(M=1.12 ; F(1,149)=175.12, p<$ 
.001). Again, there was no main effect or interaction involving betrayal (all $p$ 's $>.10$ ).

Air Bag Preference. Figure 2 presents the mean preference ratings for the air bag alternatives. An ANOVA revealed a main effect for potential betrayal, with greater preference for the lower overall risk air bag in the no betrayal condition $(M=5.45)$ than in the betrayal condition $(M=$ $2.98 ; F(1,240)=154.14, p<.001)$. There was also a significant betrayal $\times$ imagery interaction $(F(2,240=$ $5.36, p<.005)$. Follow-up contrasts showed that preference for the safer air bag differed in the betrayal conditions $(F(2$, $117)=7.62, p<.01)$ but not in the no betrayal conditions $(F(2,123)=0.08, p>.10)$. In the betrayal conditions, preference for the safer option was higher when positive imagery was present $(M=3.84)$ than when no imagery was present $(M=2.59 ; F(1,85)=12.00, p<.001)$. The presence of negative imagery in the betrayal conditions $(M$ $=2.58$ ) did not affect preference for the safer alternative relative to no imagery $(F(1,88)=0.17, p>.10)$.

Emotional Reaction to Potential Betrayal. An ANOVA revealed a main effect for betrayal on the aggregated emotion measure ( $\alpha=.90)$ with greater negative emotions reported for air bags that have a potential to betray $(M=1.77)$ compared to those that do not betray $(M=$ $1.25 ; F(1,240)=33.46, p<.01)$. Further, there was a significant betrayal $\times$ imagery interaction $(F(2,240)=$ $5.94, p<.01)$. When there was potential for betrayal, participants in the positive imagery condition experienced less negative emotion $(M=1.31)$ than participants in either the negative imagery or control conditions $(M$ 's $=2.02$ and 1.96 , respectively; $F(2,117)=8.104, p<.001)$. When there was no potential for betrayal, there was no difference in reported emotion across the three imagery conditions $(F(2,123)=0.47, p>.10)$.

\section{Discussion}

Study 2 is notable for two reasons. First, it replicated the basic betrayal aversion effect. Participants strongly preferred a higher risk option ( $2 \%$ chance of death) when the lower risk option ( $1.01 \%$ chance of death) included a small risk of betrayal. However, when the small risk of betrayal was replaced by a mathematically identical nonbetrayal risk, this choice pattern reversed. Participants showed greater preference for the normatively lower risk $(1.01 \%$ chance of death) option. Second, study 2 showed that exposure to positive imagery decreased negative emotion and decreased aversion to the low risk safety option that had a potential to betray. This result is consistent with prior research that showed an influence of emotional stimuli on decisions involving safety and risk (Andrade and Ariely 2009; Hsee and Rottenstreich 2004; Lincoln et al. 2009; Raghunathan and Pham 1999).

Negative imagery did not increase aversion to the betrayal option or negative emotional responses to it. The result may be due to a ceiling effect: betrayal aversion is already so
FIGURE 2

STUDY 2: IMAGES AND POTENTIAL BETRAYAL ON PREFERENCE FOR OVERALL LOWER RISK (1.01\%) AIR BAG OPTION

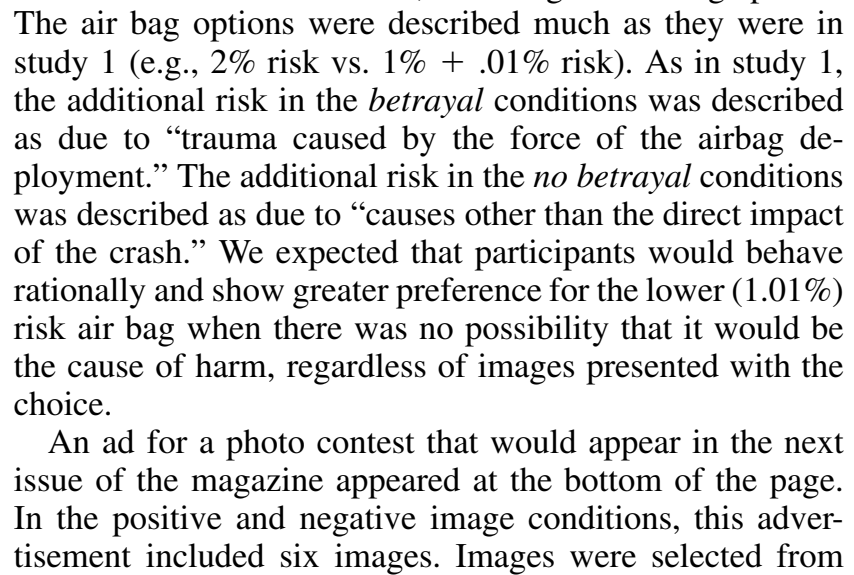

prevalent that introduction of negative imagery does little more than reinforce the evaluation of the alternatives that would be observed without it. Alternatively, the specific negative images used in this study may have been too weak to arouse strong negative emotions and therefore did not increase betrayal aversion. Regardless of which explanation is true, the observation that positive images can affect both consumers' emotions and safety choice behavior supports our thesis that a key to overcoming betrayal aversion lies in dampening the negative emotion that betrayal evokes.

\section{STUDY 3: CUES TO RATIONAL PROCESSING}

In study 3, we explore a related technique for dampening betrayal emotion and betrayal aversion. Drawing on research that shows that irrational judgments can be curtailed when relevant data are presented with graphical support (Berger 2007; Bhasker and Kumaraswamy 1990; Kleinmuntz and Schkade 1993; Liersch and McKenzie 2009), we consider whether describing safety risks with the aid of graphics will reduce emotional reactions to potential betrayal and encourage consumers to select the safer option. Using the air bag scenario, we predict that providing a graphical display of the risks associated with each of the potential air bags will reduce emotional reactions and reduce betrayal aversion.

\section{Method}

Two hundred and sixty-three individuals were recruited from the University of Michigan paid participant pool, as in study 1 , and each was paid $\$ 2$. The study used a 2 (betrayal: yes, no) $\times 2$ (risk presentation: narrative, visual) between-subjects design. The basic stimuli and dependent measures were similar to those in study 2. Participants in 
the visual risk presentation conditions received an image graphic that described the number of deaths expected out of 10,000 for each of the air bags. There was a box above the description of each air bag titled "Total deaths expected in 10,000 serious accidents." The option associated with the $2 \%$ risk contained an array of 200 tiny icons of skulls with crossbones. The option associated with the $1.01 \%$ risk contained an array of 101 skull and crossbones icons.

\section{Results}

Figure 3 presents mean preference ratings for the alternatives. Replicating study 1 and Koehler and Gershoff (2003), there was a main effect for betrayal: participants showed greater preference for the safer option when the additional risk did not involve betrayal $(M=5.10)$ versus when it involved betrayal $(M=2.96 ; F(1,259)=117.72, p<$ $.001)$.

There was also a betrayal $\times$ risk presentation interaction $(F(1,259)=4.49, p<.05)$. Follow-up contrasts showed that preference for the safer air bag differed in the betrayal conditions as a function of risk presentation $(t(129)=3.24$, $p<.01)$. In the betrayal condition preference for the safer option increased when the presentation included a visual representation of the risks $(M=3.47)$ versus when it was presented solely in narrative form $(M=2.54)$. In the no betrayal conditions presentation format did not affect preference $(t(130)=0.45, p>.10)$.

An ANOVA revealed a main effect for betrayal on the aggregated emotion measure $(\alpha=.91)$ with greater negative emotion in the betrayal condition $(M=2.13)$ than in the no betrayal condition $(M=1.41 ; F(1,259)=29.67, p<$ $.001)$. There was also a significant betrayal $\times$ risk representation interaction $(F(1,259)=7.86, p<.01)$. When there was potential for betrayal, participants in the visual risk representation condition reported less negative emotion $(M=1.86)$ than participants in the narrative risk representation condition $(M=2.36 ; F(1,129)=7.73, p<.01)$. When there was no potential for betrayal, there was no difference in emotional reactions as a function of risk representation $F(1,130)=0.83, p>.10)$.

\section{Discussion}

Study 3 provides further support for the idea that factors that dampen a decision maker's negative emotions can reduce betrayal aversion. The data showed that presenting the statistical information associated with a betrayal risk in a graphical format leads to a more cognitive and a less emotion-based evaluation of the available options. We observed a reduction in both negative emotion and betrayal aversion when we supplemented a risk narrative with a vivid graphical display of the corresponding risks.

\section{STUDY 4: SAFETY DEVICE RECIPIENT}

People who give good advice often have trouble following that same advice in their own lives. Research shows that
FIGURE 3

STUDY 3: RISK PRESENTATION AND POTENTIAL BETRAYAL ON PREFERENCE FOR OVERALL LOWER RISK (1.01\%) AIR BAG OPTION

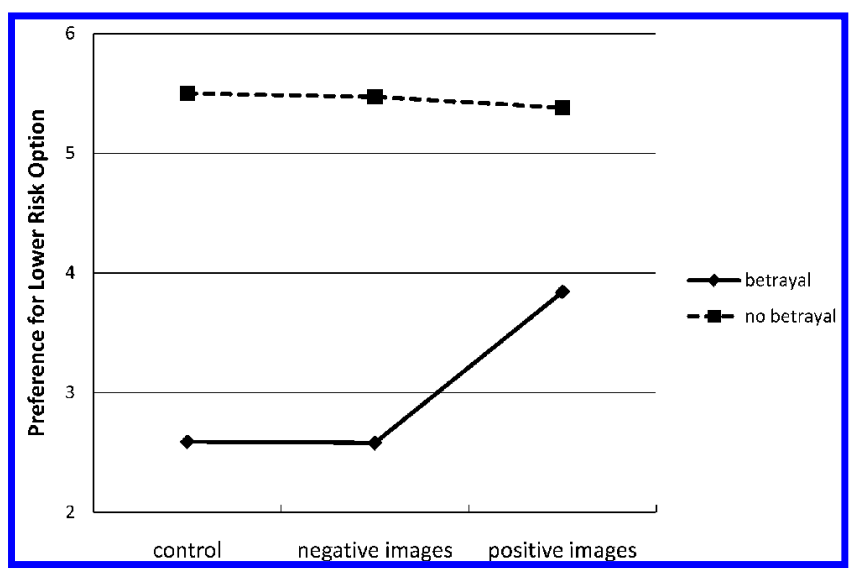

people of all ages rely on different attributes, and make different choices, depending on whether they are advising (or choosing for) someone else or making a decision that affects themselves (Hsee and Weber 1997; Kray and Gonzalez 1999; Prencipe and Zelazo 2005). Faro and Rottenstreich (2006) find that the choices people make for others are more risk neutral than those they make for themselves, a phenomenon they refer to as an "empathy gap." If an empathy gap is common in risky choice tasks, then safety product betrayal aversion might be reduced by asking decision makers to imagine that they are making safety product choices for strangers. We anticipate that this technique will dampen the negative emotions ordinarily experienced by those who contemplate betrayal options and increase preference for the lower overall risk safety option.

\section{Method}

Ninety-two individuals were recruited from the University of Michigan paid participant pool, and each was paid $\$ 3$. The study used a 2 (betrayal: yes, no) $\times 2$ (safety device recipient: self, other) between-subjects design. The basic stimuli and dependent measures were similar to those used in studies 2 and 3. The self-safety-device-recipient conditions were identical to the control conditions in studies 2 and 3 , with participants evaluating the alternatives as if they were making a choice for themselves. In the other-safetydevice-recipient conditions, participants were told that they had to choose one of the options for another (unnamed) person in the study.

\section{Results}

Figure 4 presents mean preference ratings for the alternatives. There was a main effect for betrayal condition $(F(1$, $88)=15.19, p<.001)$. Participants showed greater pref- 


\section{FIGURE 4}

STUDY 4: SAFETY DEVICE RECIPIENT AND POTENTIAL BETRAYAL ON PREFERENCE FOR OVERALL LOWER RISK (1.01\%) AIR BAG OPTION

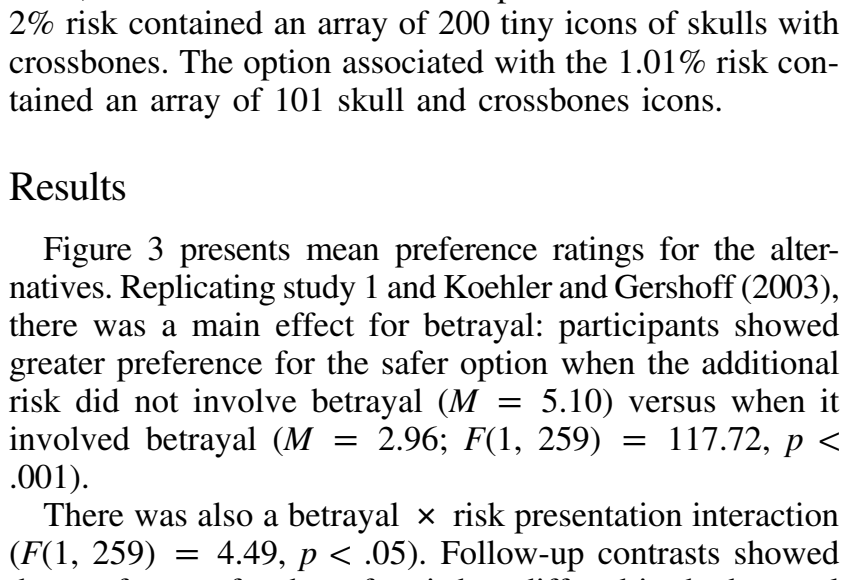

erence for the safer option (1.01\% chance of death) when the additional risk did not involve betrayal $(M=5.20)$ compared to when it did $(M=4.11)$. There was also a significant betrayal $\times$ safety device recipient interaction $(F(1,88)=4.30, p<.05)$. In the self-safety-device-recipient condition, there was a significant decrease in preference for the safer alternative in the self-choice condition when it had the potential to betray $(M=3.38)$ than when it did not $(M$ $=5.17 ; t(88)=4.07, p<.001)$. In the other-safety-devicerecipient conditions, we did not detect a significant decrease in preference for the safer alternative as a function of whether it did or did not have the potential to betray ( $M$ 's $=4.69$ and 5.24, respectively; $t(88)=1.26, p>.10)$.

Regarding the emotion measure, an ANOVA detected a main effect wherein participants showed greater negative emotion in the betrayal condition $(M=1.73)$ than in the no betrayal condition $(M=1.37 ; F(1,88)=14.67, p<$ $.001)$. We also detected a significant betrayal $\times$ safety device recipient interaction that showed that choosing for another person rather than oneself reduced the difference in emotion in the betrayal and nonbetrayal conditions $(F(1,88)$ $=14.17, p<.001)$. In the self-recipient conditions, there was greater negative emotion in the betrayal condition $(M$ $=2.04)$ compared to the nonbetrayal condition $(M=1.31$; $t(88)=2.74, p<.01)$. But in the other-recipient conditions, there was no difference in negative emotion as a function of betrayal $\left(M^{\prime} \mathrm{s}=1.42 ; F(1,88)=0.01, p>.10\right)$.

\section{Discussion}

Participants in study 4 were less likely to be betrayal averse when choosing the safety product for a stranger rather than themselves. The reduction in negative emotions reported by other-recipient participants versus the self-recipient participants is also consistent with a conclusion that other-recipient participants were more inclined to rely on
System 2 reasoning than were the more emotive self-recipient participants.

This result implies that policy makers may be able to minimize interference from the negative emotions that betrayal options cause by relying on scenarios that call to mind the safety of strangers rather than the safety of oneself or a loved one. This implication challenges the intuitive notion that risk management professionals should recommend the same options to their clients and patients that they would recommend to a close family member or themselves.

\section{STUDY 5: INDIVIDUAL DIFFERENCES IN THINKING STYLE}

Study 5 extends our examination of the role of emotion in betrayal aversion by considering the role of individual differences in reasoning style on safety product choices. Research shows that some people rely more on experiential or intuitive ways of thought (System 1) and others rely more on analytical or rational approaches (System 2; Epstein et al. 1996; Pacini and Epstein 1999). Because those who tend toward the experiential-intuitive mode are more likely to invoke emotional and heuristic ways of thought (Epstein et al. 1996; Shiloh et al. 2002), we expect that experiential thinkers will react more strongly to potential betrayals and be more likely to avoid them.

We operationalize experiential thought tendencies via scores on a version of the Faith in Intuition (FI) component of the Rational-Experiential Inventory (Epstein et al. 1996). The FI scale measures the extent to which people rely on feelings and intuitions to make judgments and decisions. We predict greater betrayal aversion among those who tend toward experiential-intuitive thinking. However, we do not expect experiential thinkers to make different safety choices than analytical thinkers when the betrayal element is removed from the decision task.

\section{Method}

One hundred and thirteen people from the University of Michigan student participant pool participated in study 5 . Each participant received extra course credit. Participants completed the five-item Faith in Intuition Scale (FI). This scale asks participants to indicate their degree of agreement with statements like "I trust my initial feelings about people" and "I believe in trusting my hunches." After a filler task, participants were randomly assigned to the betrayal or no betrayal conditions of the air bag scenario and responded to the usual dependent measures.

\section{Results}

As before, there was a main effect for betrayal: participants showed greater preference for the safer option when the additional risk did not involve betrayal $(M=5.30)$ versus when it did $(M=4.05 ; F(1,111)=22.00, p<$ $.001)$. Participants also indicated more negative emotion toward the lower risk alternative in the betrayal condition ( $M$ 
$=1.72)$ than in the nonbetrayal condition $(M=1.22 ; F(1$, $111)=21.29, p<.001)$. The five FI items were averaged to create a single FI score $(\alpha=.82)$. We included this measure in a regression along with an indicator variable for betrayal condition and a betrayal $\times$ FI interaction term. In addition to the main effect for betrayal described above, the regression revealed a main effect for FI such that higher FI scores were associated with greater preference for the safer air bag option $(t(1,109)=-3.48, p<.001)$. There was also a betrayal $\times$ FI interaction $(t(1,109)=-2.49, p<$ .05 ; see fig. 5). In the betrayal condition, higher FI scores were associated with preference for the higher risk air bag option (standardized beta $=-0.49 ; t(1,54)=-4.16 ; p$ $<.001)$. In the no betrayal condition, there was no effect of FI on air bag preference (standardized beta $=-0.09 ; t(1$, 55) $=-0.73 ; p>.10)$.

\section{Discussion}

We have argued throughout that betrayal aversion is linked to the negative emotional response people experience upon learning that an object of protection may become a source of harm. If this is true, then we would expect people who rely more on their experiential system to react more negatively to a potential product betrayal. Study 5 found this to be the case: those with higher Faith in Intuition (FI) scores were more betrayal averse. However when the betrayal risk was replaced by an equivalent nonbetrayal risk, the FI score did not predict safety preferences.

\section{GENERAL DISCUSSION}

When a safety product violates consumers' trust by causing the harm it is intended to prevent, people feel betrayed. In earlier research Koehler and Gershoff (2003) showed that the mere possibility of safety product betrayal conjures up strong emotional reactions and some surprising avoidance behavior identified as betrayal aversion, namely, a preference for higher overall risk safety products compared to lower-risk products that include a small chance of betrayal. The present article extends this research by examining the role that negative emotion plays in the production of betrayal-averse choices. We conducted a series of controlled laboratory experiments in which we dampened and/or measured negative emotion in a safety device betrayal decision task. These experiments consistently demonstrate that betrayal aversion is reduced when factors that dampen the emotional response to potential betrayals are introduced or taken into account. These factors include changing the betrayal from an action to an omission (study 1), introducing positive imagery (study 2), introducing visual representations of risk (study 3), making the decision for another rather than oneself (study 4), and intuitive thinking style (study $5)$.

Our research has implications for social policy makers and health professionals. Various government agencies are charged with protecting public safety and general welfare. These agencies frequently issue safety standards on such im-
FIGURE 5

STUDY 5: ESTIMATED REGRESSION LINES OF FAITH IN INTUITION ON PREFERENCE FOR OVERALL LOWER RISK (1.01\%) AIR BAG OPTION IN BETRAYAL AND NO-BETRAYAL CONDITIONS

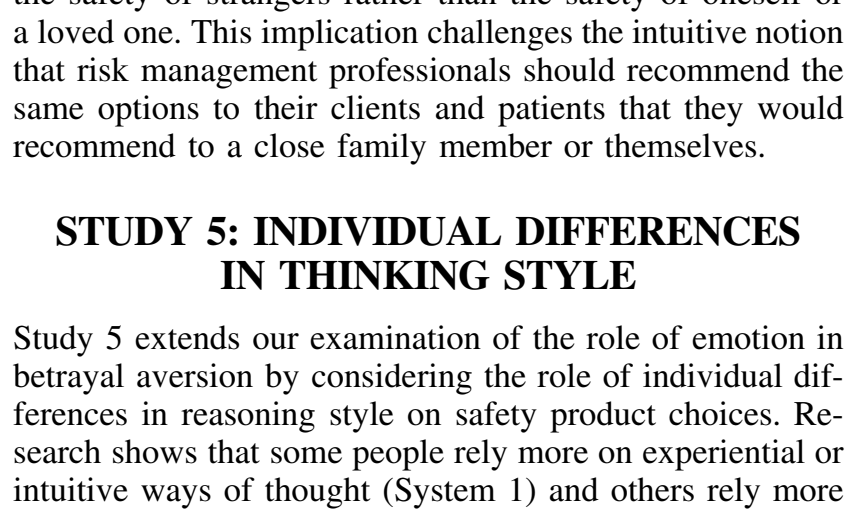

portant matters as seat belt usage in cars, helmet usage on bicycles, and vaccinations for public school children (Fischhoff 1984). Policy makers, who generally prefer alternatives that maximize overall safety, need to be sensitive to the possibility that members of the public will find some of those alternatives emotionally repugnant. Indeed, large portions of the public may act in ways that put them at increased risk. Consider the 2009 worldwide outbreak of the H1N1 influenza virus. Although prestigious health agencies like the Centers for Disease Control consistently recommended vaccinating all children for this virus, polls showed that only $40 \%$ of American parents felt that $\mathrm{H} 1 \mathrm{~N} 1$ vaccination was in their children's best interests (Healy 2009). Approximately half of the parents who did not plan to vaccinate their children expressed concern about betrayal-related effects, namely, the possibility that the vaccine itself could cause illness. Our studies suggest that one way to align the views of the general public with the recommendations of public policy makers is to minimize the impact of negative emotions and emotional reasoning on consumers. For example, the expected death toll of children that do and do not vaccinate could be represented in graphical form on billboards and other public health advertisements.

Similarly, health professionals who provide treatment plans for patients that include a risk of betrayal could be taught to resist the invitation and urge to offer opinions about how they would make the decision if they themselves were the patient. Our research suggests that this may be the wrong strategy for encouraging patients to attend to overall risks. Instead, health professionals might be advised to retain their neutrality and offer the same recommendations to their patients that they would offer to a stranger. Although such a strategy may seem strange and antithetical to a personal health care system, strangeness may be a small price to pay for a decision strategy that increases the probability of a favorable outcome. 
Of course, any strategic framing of information raises ethical and normative issues (Slovic et al. 2005). On the one hand, because all information must be framed in some way or other, one could argue that it is too costly-or even unethical-not to frame health and safety information in ways that benefit the general public (cf. Thaler and Sunstein 2008). Advocates of this view treat betrayal aversion as a judgment error that should be corrected (Sunstein 2005), perhaps via some of the techniques described herein. We accept the cost/ethics argument above but are not persuaded by the normative claim (Koehler and Gershoff 2005). It is one thing to present safety information and options in ways that are likely to maximize societal benefits or minimize overall harms. It is quite another to suggest that a consumer's safety product preferences (holding costs aside) should depend entirely upon a comparison of the overall risks of the focal harm posed by the available options. If the negative consequences of safety product betrayals reach beyond the immediate harm (e.g., by instilling within the general public a deep mistrust of manufacturers and government safety agencies), then one cannot say that consumers' safety product preferences should rely on probability of death comparisons alone. A rational person may justly believe that eliminating the collateral damage that betrayals may cause, including the emotional toll and damage to the social order, is worth trading for a small increased risk of death.

\section{REFERENCES}

Andrade, Eduardo and Dan Ariely (2009), "The Enduring Impact of Transient Emotions on Decision Making," Organizational Behavior and Human Decision Processes, 109 (2), 1-8.

Baron, Jonathan (2008), Thinking and Deciding, New York: Cambridge University Press.

$\rightarrow$ Baumeister, R. F., K. D. Vohs, C. N. DeWall, and L. Zhang (2007), "How Emotion Shapes Behavior: Feedback, Anticipation, and Reflection, Rather than Direct Causation," Personality and Social Psychology Review, 11 (2), 167-203.

$\rightarrow$ Berger, Charles R. (2007), "A Tale of Two Communication Modes: When Rational and Experiential Processing Systems Encounter Statistical and Anecdotal Depictions of Threat," Journal of Language and Social Psychology, 26 (3), 215-33.

Bhasker, S. and Kumaraswamy, A. (1990), "Graphical Techniques in Debiasing: An Exploratory Study," Information Systems Working Papers Series, No. IS-90-19, Available at SSRN, http://ssrn.com/abstract $=1289090$.

Blendon, Robert J., Gillian K. SteelFisher, John M. Benson, Kathleen J. Weldon, and Melissa J. Herrmann (2009), "Public Views of the H1N1 Vaccine," Harvard Opinion Research Program (Harvard School of Public Health, September 14-20), http://www.hsph.harvard.edu/research/horp.

$\rightarrow$ Buunk, B. (1982), "Strategies of Jealousy: Styles of Coping with Extramarital Involvement of the Spouse," Family Relations, 31 (1), 13-18.

Chaiken, Shelly and Yaacov Trope (1999), Dual-Process Theories in Social Psychology, New York: Guilford.

$\rightarrow$ Chandran, Sucharita and Geeta Menon (2004), "When a Day Means More than a Year: Effects of Temporal Framing on Judgments of Health Risk," Journal of Consumer Research, 31 (2), 375-89. $\rightarrow$ Chartrand, Tanya L., Rick B. van Baaren, and John A. Bargh (2006), "Linking Automatic Evaluation to Mood and Information Processing Style: Consequences for Experienced Affect, Impression Formation, and Stereotyping," Journal of Experimental Psychology: General, 135 (1), 70-77.

CNN (1998), "Air Bag On or Off? Now Some Can Choose" (January 19), http://articles.cnn.com/1998-01-19/us/9801_19_air .bags_1_air-bag-rearfacing-infant-seats-chuck-hurley?_s = PM:US.

$\rightarrow$ Davis, Joanne L. and Patricia A. Petretic-Jackson (2000), "The Impact of Child Sexual Abuse on Adult Interpersonal Functioning: A Review and Synthesis of the Empirical Literature," Aggression and Violent Behavior, 5 (3), 291-328.

$\rightarrow$ Drolet, Aimee and Mary Frances Luce (2004), "The Rationalizing Effects of Cognitive Load on Emotion-Based Tradeoff Avoidance," Journal of Consumer Research, 31 (1), 63-77.

Ellenberg Susan S. and Robert T. Chen (1997), "The Complicated Task of Monitoring Vaccine Safety," Public Health Reports, 112 (1), 10-20.

$\rightarrow$ Epstein, Seymour, Rosemary Pacini, Veronika Denes-Raj, and Harriet Heier (1996), "Individual Differences in Intuitive and Analytical Information Processing," Journal of Personality and Social Psychology, 71 (2), 390-405.

$\rightarrow$ Faro, David and Yuval Rottenstreich (2006), "Affect, Empathy, and Regressive Mispredictions of Others' Preferences under Risk," Management Science, 52 (4), 529-41.

$\rightarrow$ Finucane, Melissa L., Ali Alhakami, Paul Slovic, and Stephen M. Johnson (2000), "The Affect Heuristic in Judgments of Risks and Benefits," Journal of Behavioral Decision Making, 13 (1), 1-17.

$\rightarrow$ Fischhoff, Baruch (1984), "Setting Standards: A Systematic Approach to Managing Public Health and Safety Risks," Management Science, 30 (7), 823-43.

Healy, Melissa (2009), "Most Parents Won't Have Kids Get H1Ni Flu Shots, Study Finds," Los Angeles Times (September 25), http://articles.latimes.com/2009/sep/25/science/sci-parentsflu25.

$\rightarrow$ Hoffer, George E. and Steven P. Peterson (1994), "The Impact of Airbag Adoption on Relative Personal Injury and Absolute Collision Insurance Claims," Journal of Consumer Research, 20 (4), 657-62.

$\rightarrow$ Hsee, Christopher K. and Yuval Rottenstreich (2004), "Music, Pandas and Muggers: On the Affective Psychology of Value," Journal of Experimental Psychology: General, 133 (1), 23-30.

$\rightarrow$ Hsee, Christopher K. and Elke U. Weber (1997), “A Fundamental Prediction Error: Self-Others Discrepancies in Risk Preference," Journal of Experimental Psychology: General, 126 (1), 45-53.

$\rightarrow$ Kahneman, Daniel (2003), "A Perspective on Judgment and Choice," American Psychologist, 58 (9), 697-720.

Kahneman, Daniel and Shane Frederick (2002), "Representativeness Revisited: Attribute Substitution in Intuitive Judgment," in Heuristics and Biases, ed. Thomas Gilovich, Dale Griffin, and Daniel Kahneman, New York: Cambridge University Press, 49-81.

$\rightarrow$ Kleinmuntz, Don M. and David A. Schkade (1993), "Information Displays and Decision Processes," Psychological Science, 4 (4), 221-27.

$\rightarrow$ Koehler, Jonathan J. and Andrew D. Gershoff (2003), "Betrayal Aversion: When Agents of Protection Become Agents of 
Harm," Organizational Behavior and Human Decision Processes, 90 (2), 244-61.

$\rightarrow-$ (2005), "Betrayal Aversion Is Reasonable," Behavioral and Brain Sciences, 28 (4), 556-57.

$\rightarrow$ Kray, Laura (2000), "Contingent Weighting in Self-Other Decision Making," Organizational Behavior and Human Decision Processes, 83 (1), 82-106.

$\rightarrow$ Kray, Laura and Richard Gonzalez (1999), "Differential Weighting in Choice versus Advice: I'll Do This, You Do That," Journal of Behavioral Decision Making, 12 (3), 207-17.

Lang, Peter J., Margaret M. Bradley, and Bruce N. Cuthbert (2005), "International Affective Picture System (IAPS): Digitized Photographs, Instruction Manual and Affective Ratings," Technical Report A-6, University of Florida, Gainesville.

$\rightarrow$ Liersch, Michael J. and Craig R. M. McKenzie (2009), "Duration Neglect by Numbers: And Its Elimination by Graphs," Organizational Behavior and Human Decision Processes, 108 (2), 303-14.

Lincoln, Tania M., Jennifer Lange, Julia Burau, Cornelia Exner, and Steffen Moritz (2009), "The Effect of State Anxiety on Paranoid Ideation and Jumping to Conclusions: An Experimental Investigation," Schizophrenia Bulletin, Advance Access electronically published May 8.

$\rightarrow$ Loewenstein, George F. (1996), "Out of Control: Visceral Influences on Behavior," Organizational Behavior and Human Decision Processes, 65 (3), 272-92.

$\rightarrow$ Loewenstein, George F., Elke U. Weber, Christopher K. Hsee, and Ned Welch (2001), "Risk as Feelings," Psychological Bulletin, 127 (2), 267-86.

Matthews, Mark (1999), "A Snarl Over Bear Repellent Leaves Consumers Confused," Washington Post (April 12), A9.

Medvec, Victoria H., Kathleen L. Valley, and Richard Thaler (1999), "Concession Aversion: A Story of Loss and Betrayal," Harvard Business School Working Papers Collection (HBS No. 00-026), http://www.hbs.edu/research/facpubs/workingpapers/abstracts/9900/00-026.html.

$\rightarrow$ Mellers, Barbara A., Allan Schwarz, Katty Ho, and Illana Ritov (1997), "Decision Affect Theory: Emotional Reactions to the Outcomes of Risky Options," Psychological Science, 8 (6), 423-29.

$\rightarrow$ Menon, Geeta, Lauren G. Block, and Suresh Ramanathan (2002), "We're at as Much Risk as We Are Led to Believe: Effects of Message Cues on Judgments of Health Risk," Journal of Consumer Research, 28 (4), 533-49.

Meyer, Mary and Tremika Finney (2005), "Who Wants Air Bags?" Chance, 18 (2), 3-16.

$\rightarrow$ Pacini, Rosemary and Seymour Epstein (1999), "The Relation of Rational and Experiential Information Processing Styles to Personality, Basic Beliefs, and the Ratio-Bias Phenomenon," Journal of Personality and Social Psychology, 76 (6), 972-87.

$\rightarrow$ Pillutla, Madan N. and J. Keith Murnighan (1996), "Unfairness, Anger, and Spite: Emotional Rejections of Ultimatum Offers," Organizational Behavior and Human Decision Processes, 68 (3), 208-24.

$\rightarrow$ Prencipe, Angela and Philip David Zelazo (2005), "Development of Affective Decision Making for Self and Other Evidence for the Integration of First- and Third-Person Perspectives," Psychological Science, 16 (7), 501-5.

Prentice, Robert A. and Jonathan J. Koehler (2003), “A Normality
Bias in Legal Decision Making," Cornell Law Review, 88 (3), 583-650.

$\rightarrow$ Raghunathan, Rajagopal and Michel Tuan Pham (1999), “All Negative Moods Are Not Equal: Motivational Influences of Anxiety and Sadness on Decision Making," Organizational Behavior and Human Decision Processes, 71 (1), 56-77.

Reuters. 2010. "Chrysler to Fix Airbags in Some 355,500 Minivans" (February 24), http://www.reuters.com/article/idUSTRE61N5MM20100224.

$\rightarrow$ Richard, Rene, Joop van der Pligt, and Nanne de Vries (1996), "Anticipated Regret and Time Perspective: Changing Sexual Risk-Taking Behavior," Journal of Behavioral Decision Making, 9 (3), 185-99.

$\rightarrow$ Robinson, Sandra L. and Elizabeth W. Morrison (2000), "The Development of Psychological Contract Breach and Violation: A Longitudinal Study," Journal of Organizational Behavior, 21 (5), 525-46.

$\rightarrow$ Rottenstreich, Yuval and Ran Kivetz (2006), "On Decision Making without Likelihood Judgment," Organizational Behavior and Human Decision Processes, 101 (1), 74-88.

$\rightarrow$ Sanfey, Alan G., James K. Rilling, Jessica A. Aronson, Leigh E. Nystrom, and Jonathan D. Cohen (2003), "The Neural Basis of Economic Decision-Making in the Ultimatum Game," Science, 300 (5626), 1755-58.

Sepkowitz, Kent (2004), "Why Good Friends Don't Always Make Good Doctors," New York Times (November 30).

$\rightarrow$ Shiloh, Shoshana, Efrat Salton, and Dana Sharabi (2002), "Individual Differences in Rational and Intuitive Thinking Styles as Predictors of Heuristic Responses and Framing Effects," Personality and Individual Differences, 32 (3), 415-29.

$\rightarrow$ Sloman, Steven A. (1996), "The Empirical Case for Two Systems of Reasoning," Psychological Bulletin, 119 (1), 3-22.

$\rightarrow$ Slovic, Paul and Ellen Peters (2006), "Risk Perception and Affect," Current Directions in Psychological Science, 15 (6), 322-25.

$\rightarrow$ Slovic, Paul, Ellen Peters, Melissa L. Finucane, and Donald G. MacGregor (2005), "Affect, Risk and Decision Making," Health Psychology, 24 (4), S35-S40.

Sunstein, Cass (2005), "Moral Heuristics," Behavioral and Brain Science, 28 (4), 531-73.

Thaler, Richard H. and Cass R. Sunstein (2008), Nudge: Improving Decisions about Health, Wealth, and Happiness, New Haven, CT: Yale University Press.

$\rightarrow$ Thompson, Craig J. (2005), "Consumer Risk Perceptions in a Community of Reflexive Doubt," Journal of Consumer Research, 32 (September), 235-48.

$\rightarrow$ van Gelder, Jean-Louis, Reinout E. de Vries, and Joop van der Pligt (2009), "Evaluating a Dual-Process Model of Risk: Affect and Cognition as Determinants of Risky Choice," Journal of Behavioral Decision Making, 22 (1), 45-61.

$\rightarrow$ Watson, David, Lee Anna Clark, and Auke Tellegen (1988), "Development and Validation of Brief Measures of Positive and Negative Affect: The PANAS Scales," Journal of Personality and Social Psychology, 54 (6), 1063-70.

$\rightarrow$ Weber, Elke U. and Richard A. Milliman (1997), "Perceived Risk Attitudes: Relating Risk Perception to Risky Choice," Management Science, 43 (2), 123-44.

$\rightarrow$ Zeelenberg, Marcel, Joop van der Pligt, and Nanne de Vries (2000), "Attributions of Responsibility and Affective Reactions to Decision Outcomes," Acta Psychologica, 104 (3), 303-15. 
Harm," Organizational Behavior and Human Decision Processes, 90 (2), 244-61.

$\rightarrow-$ (2005), "Betrayal Aversion Is Reasonable," Behavioral and Brain Sciences, 28 (4), 556-57.

$\rightarrow$ Kray, Laura (2000), "Contingent Weighting in Self-Other Decision Making," Organizational Behavior and Human Decision Processes, 83 (1), 82-106.

$\rightarrow$ Kray, Laura and Richard Gonzalez (1999), "Differential Weighting in Choice versus Advice: I'll Do This, You Do That," Journal of Behavioral Decision Making, 12 (3), 207-17.

Lang, Peter J., Margaret M. Bradley, and Bruce N. Cuthbert (2005), "International Affective Picture System (IAPS): Digitized Photographs, Instruction Manual and Affective Ratings," Technical Report A-6, University of Florida, Gainesville.

$\rightarrow$ Liersch, Michael J. and Craig R. M. McKenzie (2009), "Duration Neglect by Numbers: And Its Elimination by Graphs," Organizational Behavior and Human Decision Processes, 108 (2), 303-14.

Lincoln, Tania M., Jennifer Lange, Julia Burau, Cornelia Exner, and Steffen Moritz (2009), "The Effect of State Anxiety on Paranoid Ideation and Jumping to Conclusions: An Experimental Investigation," Schizophrenia Bulletin, Advance Access electronically published May 8.

$\rightarrow$ Loewenstein, George F. (1996), "Out of Control: Visceral Influences on Behavior," Organizational Behavior and Human Decision Processes, 65 (3), 272-92.

$\rightarrow$ Loewenstein, George F., Elke U. Weber, Christopher K. Hsee, and Ned Welch (2001), "Risk as Feelings," Psychological Bulletin, 127 (2), 267-86.

Matthews, Mark (1999), "A Snarl Over Bear Repellent Leaves Consumers Confused," Washington Post (April 12), A9.

Medvec, Victoria H., Kathleen L. Valley, and Richard Thaler (1999), "Concession Aversion: A Story of Loss and Betrayal," Harvard Business School Working Papers Collection (HBS No. 00-026), http://www.hbs.edu/research/facpubs/workingpapers/abstracts/9900/00-026.html.

$\rightarrow$ Mellers, Barbara A., Allan Schwarz, Katty Ho, and Illana Ritov (1997), "Decision Affect Theory: Emotional Reactions to the Outcomes of Risky Options," Psychological Science, 8 (6), 423-29.

$\rightarrow$ Menon, Geeta, Lauren G. Block, and Suresh Ramanathan (2002), "We're at as Much Risk as We Are Led to Believe: Effects of Message Cues on Judgments of Health Risk," Journal of Consumer Research, 28 (4), 533-49.

Meyer, Mary and Tremika Finney (2005), "Who Wants Air Bags?" Chance, 18 (2), 3-16.

$\rightarrow$ Pacini, Rosemary and Seymour Epstein (1999), "The Relation of Rational and Experiential Information Processing Styles to Personality, Basic Beliefs, and the Ratio-Bias Phenomenon," Journal of Personality and Social Psychology, 76 (6), 972-87.

$\rightarrow$ Pillutla, Madan N. and J. Keith Murnighan (1996), "Unfairness, Anger, and Spite: Emotional Rejections of Ultimatum Offers," Organizational Behavior and Human Decision Processes, 68 (3), 208-24.

$\rightarrow$ Prencipe, Angela and Philip David Zelazo (2005), "Development of Affective Decision Making for Self and Other Evidence for the Integration of First- and Third-Person Perspectives," Psychological Science, 16 (7), 501-5.

Prentice, Robert A. and Jonathan J. Koehler (2003), “A Normality
Bias in Legal Decision Making," Cornell Law Review, 88 (3), 583-650.

$\rightarrow$ Raghunathan, Rajagopal and Michel Tuan Pham (1999), “All Negative Moods Are Not Equal: Motivational Influences of Anxiety and Sadness on Decision Making," Organizational Behavior and Human Decision Processes, 71 (1), 56-77.

Reuters. 2010. "Chrysler to Fix Airbags in Some 355,500 Minivans" (February 24), http://www.reuters.com/article/idUSTRE61N5MM20100224.

$\rightarrow$ Richard, Rene, Joop van der Pligt, and Nanne de Vries (1996), "Anticipated Regret and Time Perspective: Changing Sexual Risk-Taking Behavior," Journal of Behavioral Decision Making, 9 (3), 185-99.

$\rightarrow$ Robinson, Sandra L. and Elizabeth W. Morrison (2000), "The Development of Psychological Contract Breach and Violation: A Longitudinal Study," Journal of Organizational Behavior, 21 (5), 525-46.

$\rightarrow$ Rottenstreich, Yuval and Ran Kivetz (2006), "On Decision Making without Likelihood Judgment," Organizational Behavior and Human Decision Processes, 101 (1), 74-88.

$\rightarrow$ Sanfey, Alan G., James K. Rilling, Jessica A. Aronson, Leigh E. Nystrom, and Jonathan D. Cohen (2003), "The Neural Basis of Economic Decision-Making in the Ultimatum Game," Science, 300 (5626), 1755-58.

Sepkowitz, Kent (2004), "Why Good Friends Don't Always Make Good Doctors," New York Times (November 30).

$\rightarrow$ Shiloh, Shoshana, Efrat Salton, and Dana Sharabi (2002), "Individual Differences in Rational and Intuitive Thinking Styles as Predictors of Heuristic Responses and Framing Effects," Personality and Individual Differences, 32 (3), 415-29.

$\rightarrow$ Sloman, Steven A. (1996), "The Empirical Case for Two Systems of Reasoning," Psychological Bulletin, 119 (1), 3-22.

$\rightarrow$ Slovic, Paul and Ellen Peters (2006), "Risk Perception and Affect," Current Directions in Psychological Science, 15 (6), 322-25.

$\rightarrow$ Slovic, Paul, Ellen Peters, Melissa L. Finucane, and Donald G. MacGregor (2005), "Affect, Risk and Decision Making," Health Psychology, 24 (4), S35-S40.

Sunstein, Cass (2005), "Moral Heuristics," Behavioral and Brain Science, 28 (4), 531-73.

Thaler, Richard H. and Cass R. Sunstein (2008), Nudge: Improving Decisions about Health, Wealth, and Happiness, New Haven, CT: Yale University Press.

$\rightarrow$ Thompson, Craig J. (2005), "Consumer Risk Perceptions in a Community of Reflexive Doubt," Journal of Consumer Research, 32 (September), 235-48.

$\rightarrow$ van Gelder, Jean-Louis, Reinout E. de Vries, and Joop van der Pligt (2009), "Evaluating a Dual-Process Model of Risk: Affect and Cognition as Determinants of Risky Choice," Journal of Behavioral Decision Making, 22 (1), 45-61.

$\rightarrow$ Watson, David, Lee Anna Clark, and Auke Tellegen (1988), "Development and Validation of Brief Measures of Positive and Negative Affect: The PANAS Scales," Journal of Personality and Social Psychology, 54 (6), 1063-70.

$\rightarrow$ Weber, Elke U. and Richard A. Milliman (1997), "Perceived Risk Attitudes: Relating Risk Perception to Risky Choice," Management Science, 43 (2), 123-44.

$\rightarrow$ Zeelenberg, Marcel, Joop van der Pligt, and Nanne de Vries (2000), "Attributions of Responsibility and Affective Reactions to Decision Outcomes," Acta Psychologica, 104 (3), 303-15. 